\title{
DESIGN SUSTENTÁVEL E GESTÃO DO DESIGN: INTERFACES E ARESTAS
}

\author{
Maria Adircila Starling Sobreira \\ Centro Universitário UNA \\ maria.adircila@prof.una.br \\ Patrícia Santos Delgado \\ Politecnico di Torino \\ paty.delgado@hotmail.com
}

Resumo: A gestão do design e o design sustentável são amplamente discutidos pela comunidade acadêmica. Ambas estratégias são reconhecidas pelo seu aspecto holístico na resolução de desafios no âmbito de diferenciação empresarial. O presente trabalho tem como principal objetivo mapear como as duas áreas podem se complementar e quando se distanciam. Para tal foi feita uma pesquisa bibliográfica, apresentando os principais conceitos de ambas, e foram analisados seus pontos de convergência e divergência. Foi observado que ambas prezam a visão sistêmica buscando otimização de custos e diferenciação dos produtos, porém se divergem quanto ao consumo: A gestão do design preza o aumento do consumo e dos produtos, enquanto o design sustentável preza o consumo consciente. Outra divergência encontrada foi quanto ao uso de recursos: embora ambas estratégias otimizem recursos, a gestão do design o faz visando redução de custos e aumento dos lucros, enquanto o design sustentável visa o uso consciente, diminuindo assim os impactos ambientais. Observou-se que os benefícios da implementação da gestão do design e do design sustentável são muito próximos, o que os divergem são seus objetivos. No entanto, é possível aplicá-los de forma concomitante, desde que levando em consideração a missão e a visão empresarial.

Palavras-chave: design sustentável; gestão do design; diferenciação empresarial.

Abstract: Design management and sustainable design are widely debated within the academic community. Both strategies are recognized for their holistic aspect in overcoming challenges within corporate differentiation. The present study proposes, as its main objective, to map how the two areas may complement each other and how they diverge. In such endeavor, a bibliographic review was conducted presenting the main concepts in both strategies, analyzing their points of convergence and divergence. It was observed that both appeal highly to a systemic view seeking optimization of cost and differentiation of products, however they diverge as to the 
consumption: Design management seeks to increase consumption while sustainable design looks forward to conscientious consumption. Another divergence is found in regard of resource use. While both strategies seek to optimize the expenditure of resources, design management does so for the purpose of cost reduction and increase of profit, white sustainable design seeks conscientious use, diminishing environmental impacts. It has been observed that the benefits from implementing strategies of design management and sustainable design are very close, what makes them diverge are their objectives. However, it is possible to apply them concomitantly, as long as holding in consideration the company's mission and corporate vision.

Keywords: Sustainable design; design management; corporate differentiation.

\section{INTRODUÇÃO}

A gestão do design e o design sustentável são conceitos muito difundidos tanto nas universidades quanto no meio empresarial. A concorrência global exige competitividade e essas ferramentas são apontadas para suprir tal necessidade. No entanto, por mais que a cada tema seja dada a devida atenção em estudos e publicações, persiste uma pungente carência na análise do enlace entre as questões: pouco se discute a relação entre gestão do design e design sustentável, quais são seus pontos de tangência e como podem ser usadas concomitantemente.

O objetivo deste artigo é apresentar os principais conceitos de gestão do design e design sustentável, observar onde se encontram e onde se distanciam. Tal análise comparativa foi realizada através de revisão bibliográfica, baseada em artigos científicos publicados nos últimos dez anos. Desta forma inicia-se um diálogo entre as duas ferramentas e mostra como ambas podem contribuir para aumentar a competitividade em uma empresa. Faz-se necessário diferenciar tais ferramentas nesse cenário de concorrência global, e será analisado como, juntas, elas se complementam e alcançam tal diferenciação.

PETERSEN, KIM \& MOZOTA (2015) apontam o design como uma forma de alavancar recursos através da diferenciação e criação, uma vez que o mundo está cada vez mais plano e a competição de mercado mais acirrada.

\section{GESTÃO DO DESIGN}

A Gestão do Design é caracterizada pela identificação e comunicação de processos e caminhos pelos quais o design pode agregar valor para a empresa. É importante maximizar o valor percebido pelos clientes e funcionários da empresa e tornar sua marca e identidade forte ao menor custo. Desta forma pode-se perceber o papel estratégico da gestão do design nas corporações, principalmente numa época de concorrência acirrada e global.

TEIXEIRA (2005 apud CARNASCIALI) caracteriza a gestão do design como uma dimensão ampliada do design, baseada na estratégia empresarial orientada para o 
design visto de forma sistêmica, associando produto, serviço e comunicação de forma a auxiliar a empresa a se inserir no mercado.

BORJA DE MOZOTA (2006 apud PLENTZ \& BERNARDES) corrobora com Teixeira, afirmando que o design deve ser integrado na estratégia empresarial, em todos os níveis da organização. Desta maneira, com a integração dos setores envolvidos em uma empresa, o desempenho empresarial será influenciado positivamente com o desenvolvimento de produtos.

As indústrias que adotam a gestão do design tornam seus produtos diferenciados e racionalizam os custos de produção. Segundo MARTINS \& MERINO (2008):

O potencial da gestão estratégica deve ser incorporado ao processo de produção desde a concepção da estratégia da empresa, passando pela concepção do produto e em todas as fases do ciclo de vida, integrando com outras áreas, e sob todos os aspectos em que possa ser aplicado como marca, identidade visual, embalagem de produto, embalagem de transporte, comunicação, material de apoio de vendas, arquitetura, entre outras, ao que chama Gestão do Design.

Observa-se que integração é a palavra chave da gestão do design. É importante visualizar todo o processo, todo o sistema que a empresa está inserida para que a gestão aconteça de forma eficaz. Ou seja, a gestão do design exige uma visão holística da empresa, mercado e processos e exige interdisciplinaridade. Segundo AVEDANO apud MARTINS \& MERINO (2008)

A Gestão do Design desenvolve-se no contexto: sociedade, mercado e a empresa: na empresa acontece o ato de projetar (desenvolvido por consultoria ou dentro da sua organização); o mercado é o âmbito no qual a empresa atinge seus objetivos; a sociedade fornece suporte para o mercado e para a empresa, originando seu próprio programa de necessidades, que nem sempre coincide com os objetivos da empresa.

O contexto precisa ser estudado pelo gestor do design, a fim de tomar as melhores decisões para a empresa, no âmbito interno - empresa; e no externo mercado e sociedade. O Design Council (2013 apud CARNASCIALI) revela que "a definição de design em relação ao negócio está se ampliando cada vez mais e englobando quase todos os aspectos do negócio."

Para essa pesquisa, considerou-se que a gestão do design pode ser tratada pelos processos estratégicos e operacionais: gestão estratégica do design, que é aplicada na estrutura organizacional e gestão operacional do design, aplicada no desenvolvimento de novos produtos. Os dois níveis são fundamentais para a que a gestão do design aconteça de forma eficaz e integrada ao contexto (empresa, mercado e sociedade) onde está inserida. No entanto alguns autores citados por CARNASCIALI (DME, 2013; COSTA, KLÖPSCH, MOZOTA, 2011; BEST, 2006; MARTINS, MERINO, 2011; KISTMANN, 2001; RODA, KRUCKEN, 2004) incluem um terceiro nível, o nível tático, que "deve estabelecer meios para alinhar os projetos de design do nível operacional à filosofia, política e as estratégias organizacionais".

A gestão do design a nível estratégico é direcionada ao gerenciamento pelo design na empresa, de forma a integrar produto e imagem; design e estratégia. Suas principais funções são estruturar projetos e atividades, prazos, pessoal, orçamento, além de acompanhar todo o projeto, da concepção ao túmulo do mesmo. Nesse 
acompanhamento a equipe obterá importantes feedbacks de todo o contexto em que atua (empresa, mercado, sociedade) e isso se traduz em forma de conhecimento para a empresa. Gerenciar o design de forma estratégica inclui gerenciar informações e percepções dos envolvidos deste contexto. BEST (2006 apud CARNASCIALI) mostra que na gestão de design no nível estratégico o design deve estar alinhado com a missão e as estratégias da organização.

A gestão do design a nível operacional é voltada para o processo de design e segundo MOZOTA apud MARTINS \& MERINO, (2008), correspondem a cinco fases com objetivos definidos, conforme Quadro 01:

Quadro 1: Processos Criativos do Design

\begin{tabular}{|l|l|l|}
\hline FASE DO PROCESSO & OBJETIVO & PRODUTOS VISUAIS \\
\hline 0 - Investigação & Ideia & Briefing ou caderno de representação \\
\hline $\mathbf{1}$ - Pesquisa & Conceito & Conceito Visual \\
\hline $\mathbf{2}$ - Exploração & Escolha do estilo & Rafes, layouts, modelos ou maquetes \\
\hline $\mathbf{3}$ - Desenvolvimento & Protótipo, detalhe & Traços técnicos, maquete de validação \\
\hline $\mathbf{4}$ - Realização & Teste & Documento de execução \\
\hline $\mathbf{5}$ - Avaliação & Produção & Ilustração \\
\hline
\end{tabular}

Fonte: MOZOTA apud MARTINS E MERINO, 2008

Os dois níveis de gestão do design têm funções bem específicas, e devem estar sempre integrados. MAGALHÃES apud MARTINS \& MERINO (2008) desenvolveu um quadro comparativo entre a gestão operacional e estratégica (Quadro 2).

Quadro 2 - Comparativo entre design operacional e design estratégico.

\begin{tabular}{|l|l|}
\hline DESIGN OPERACIONAL & DESIGN ESTRATÉGICO \\
\hline Ação a partir de uma proposta inicial dada & $\begin{array}{l}\text { Ação desde proposta do projeto, concepção e demais } \\
\text { etapas envolvidas no processo }\end{array}$ \\
\hline Ação isolada, habilitação específica & $\begin{array}{l}\text { Ação catalisadora de conhecimentos envolvidos no } \\
\text { processo, integração }\end{array}$ \\
\hline Pensamento fracionado & Pensamento global \\
\hline Eficiência do Design & Eficiência + Eficácia do design \\
\hline Desenvolver corretamente o produto & Desenvolver o produto certo \\
\hline Ênfase nas necessidades do usuário do produto & $\begin{array}{l}\text { Ênfase nas necessidades, desejos e conveniências do } \\
\text { beneficiário do produto (incluindo cliente, consumidor, } \\
\text { usuário, fabricante, fornecedor e sociedade). Concorrente } \\
\text { como referência }\end{array}$ \\
\hline Ênfase na solução de problemas & $\begin{array}{l}\text { Monitoramento dos problemas e prospecção das } \\
\text { oportunidades }\end{array}$ \\
\hline $\begin{array}{l}\text { Processo de dentro para fora do produto - a forma } \\
\text { segue a função }\end{array}$ & $\begin{array}{l}\text { Processo de fora para dentro do produto - a forma segue } \\
\text { a mensagem (o que o público percebe) }\end{array}$ \\
\hline Solução dos problemas físicos do produto & \begin{tabular}{l} 
Posicionamento emocional do produto \\
\hline
\end{tabular}
\end{tabular}

Fonte: MAGALHÃES apud MARTINS e MERINO 2008

Nota-se que o design operacional foca em detalhes, o estratégico foca no global; o primeiro busca excelência na solução enquanto produto, o segundo busca 
solucionar lacunas de mercado e sociedade. São focos diferentes que precisam caminhar lado a lado, no mesmo ritmo para que a gestão do design seja aplicada com sucesso.

\section{DESIGN SUSTENTÁVEL}

A Word Commission for Environment and Development (WECD), introduziu o termo sustentabilidade ambiental em 1987, e se refere "às condições sistêmicas segundo as quais, em nível regional e planetário, as atividades humanas não devem interferir nos ciclos naturais em que se baseia tudo o que a resiliência do planeta permite e, ao que será transmitido às gerações futuras" (MANZINI \& VEZZOLI, 2002 apud KLONH, 2009). A mesma instituição considera desenvolvimento sustentável aquele que atende as necessidades atuais sem comprometer a capacidade das gerações futuras de atender as suas próprias necessidades. CHAVES (2009) mostra que "sustentabilidade não é mais resumida a argumentos ambientais afrontados de forma pontual, mas é uma questão sistêmica, na qual todos os elementos estão interligados. Desenvolvimento sustentável é um tema inerente a três dimensões que podem ser resumidos nos três pilares da sustentabilidade, as dimensões econômica, ambiental e social".

A sustentabilidade tem se tornado uma estratégia imperativa no século XXI, como afirma LEE \& BELL (2015). Porém mesmo reconhecendo a importância da sustentabilidade, a implementação de uma estratégia eficaz para alcançar tal patamar se mostra um desafio.

O design tem papel fundamental no desenvolvimento sustentável, uma vez que lida com matérias prima e processos de transformação, e ainda mais, lida com consumo e sociedade. Segundo GUELERE FILHO (2009),

O ecodesign pode ser definido como uma abordagem que visa desenvolver produtos ecológicos sem comprometer critérios como desempenho, funcionalidade, tempo de desenvolvimento, segurança, estética, qualidade e custo, critérios esses essenciais ao êxito comercial de qualquer produto.

O mesmo autor defende o ecodesign como uma abordagem proativa da sustentabilidade, uma vez que trata das questões ambientais nas fases iniciais de desenvolvimento de novos produtos, onde se encontram maiores oportunidades de melhorias de projetos com objetivos de minimizar impactos ambientais ao longo de todo o ciclo de vida do produto. Grande parte (60\% a $80 \%)$ do impacto ambiental do produto é estabelecida nas fases iniciais de desenvolvimento.

Como observou CHAVES (2009): "Hoje em dia, observa-se que o design para a sustentabilidade assumiu dois distintos percursos para responder aos desafios da busca por um desenvolvimento sustentável: o caminho das inovações incrementais e o das inovações radicais."

Por inovações incrementais (evolucionárias) entende-se o caminho que o design sustentável faz para se tornar aplicáveis seus métodos e ferramentas, uma vez que existem conhecimentos consolidados na academia e em alguns setores produtivos. Mas como foram desenvolvidos para uso geral, faz-se necessárias adaptações para cada setor, empresa ou produto, ou seja, adaptações puntuais. São pequenas mudanças em processos e produtos, acontecem de forma contínua e dependem muito de inovações e possibilidades tecnológicas. Devido justamente ao 
seu caráter incremental, são mais facilmente inseridos, utilizam menor tempo e custo para implementação, sendo este último aspecto o de maior interesse para a aceitação de requisitos ambientais nas empresas.

Enquanto as inovações incrementais podem ser consideradas redesign do existente, as mudanças radicais (revolucionárias) buscam rupturas, não são contínuas e costumam estar relacionadas a novas descobertas. Provocam transformações nos comportamentos, sociedade e tecnologia. As inovações radicais voltadas para sustentabilidade tendem a buscar mudanças no padrão de consumo, como por exemplo, o sistema produto-serviço e a desmaterialização do consumo. Segundo CHAVES (2009), "O outro percurso que o design para a sustentabilidade tem assumido é o de inovações radicais, como a desmaterialização de produtos, a oferta de soluções através de serviços e a busca por alternativas para um consumo mais responsável."

No entanto,

\begin{abstract}
Existem múltiplas e diferentes abordagens para se chegar a um desenvolvimento sustentável, entre os extremos da abordagem 'evolucionária' e 'revolucionária'. É clara a necessidade de uma mudança drástica, mas ao mesmo tempo, esta mudança não pode excluir uma continuidade do presente modelo de produção. Assim, todos os esforços, sejam na área técnica ou relacionados com mudanças sociais e de comportamento, são aceitos como possibilidades viáveis. (CHAVES, 2009)
\end{abstract}

Faz-se necessário então, entender a cultura empresarial, sua visão, missão e valores, bem como o contexto em que está inserida para se propor medidas, drásticas ou suaves, para atingir um patamar sustentável.

As culturas empresariais podem ser alteradas através do esforço da liderança, apesar da complexidade e tempo necessário, como afirma Schein (2010 apud LEE \& BELL). Atkinson (2012 apud LEE \& BELL) acrescenta que a mudança cultural exige uma abordagem multinível, e deve começar no topo, ajustando missão, visão, valores, metas e estratégias, e complementado por práticas organizacionais em toda a empresa. Eccles et al (2012 apud LEE \& BELL) vai além e revela que a cultura sustentável em uma empresa pode melhorar sua performance de mercado. $\mathrm{O}$ autor afirma que em pesquisas recentes foi detectado que empresas com políticas ambientais e sociais superam significativamente seus concorrentes a longo prazo, tanto no mercado de ações quanto na contabilidade.

\title{
4. DESIGN SUSTENTÁVEL E GESTÃO DO DESIGN: INTERFACES E ARESTAS
}

Pelo breve panorama traçado anteriormente pode-se notar interfaces entre a gestão do design e o design sustentável. Ambas as ferramentas atuam de forma sistêmica e integrada na empresa, buscam diferenciação para a empresa e produtos, racionalizam custos de produção e atuam na estratégia empresarial, bem como na parte operacional. Possuem íntima relação com inovação e criação de valor e devem estar coerentes com o contexto interno e externo em que estão inseridas.

Empresas com gestão bem estruturadas têm maior chance de implementar a gestão do design com êxito, uma vez que têm know-how em gerenciamento e ferramentas administrativas (Marketing, Logística, Visão de futuro, entre outras), tão bem-vindas para se gerenciar o design. E quanto mais estruturado o processo de desenvolvimento de produtos em uma empresa, melhores as oportunidades de se 
implementar design sustentável (GUELERE FILHO, 2009). Notadamente, uma ferramenta (gestão do design) abre caminho para a inserção da outra (design sustentável).

A criação de valor é um dos principais objetivos de ambas as ferramentas. A empresa que aplica design sustentável, além de agregar valor para seus clientes, que usualmente são pessoas ou empresas com engajamento ambiental e social tem maiores facilidades de exportação de seus produtos, uma vez que vários países exigem certificações ambientais. $O$ design sustentável também cria preferências e facilidades para a empresa em fazer financiamentos e até mesmo para abrir capital na Bolsa de Valores. Segundo a Lei da Política Nacional de Meio Ambiente (Lei Federal 6.938/81) as entidades e órgãos de incentivos governamentais devem condicionar a aprovação de projetos de financiamento apenas a empreendimentos que cumpram as normas, os critérios e os padrões expedidos pelos órgãos ambientais. Logo os benefícios da implementação dessa ferramenta são superiores a agregar valor e reduzir custos.

A gestão do design também oferece benefícios além: a empresa que implementa essa ferramenta fortalece sua identidade e fideliza clientes e fornecedores, tem maior controle sobre sua estratégia empresarial e tem maior capacidade de transparecer à sociedade qual é essa estratégia.

Outra interface notada se relaciona aos níveis de gestão do design e design sustentável: a gestão estratégica se relaciona com inovação radical do design sustentável, uma vez que atua mais em comportamento e tendência, monitorando problemas e buscando oportunidades inovadoras. Já a gestão operacional se relaciona com a inovação incremental, uma vez que atua mais em projetos e oferece soluções puntuais e customizadas para cada caso.

A questão do consumo é a grande aresta entre as duas ferramentas. Ambas buscam melhorar a eficiência da empresa e o valor percebido pelo cliente, porém com objetivos diferentes. Um dos principais objetivos da gestão do design é aumentar a competitividade da empresa, melhorar o lançamento de produtos e aumento de consumo; já o design sustentável busca o consumo consciente, uso mais racional dos produtos, seja por melhorar sua durabilidade ou associar ao mesmo serviços, desmaterializando o consumo.

Outra aresta percebida entre as duas ferramentas se relaciona aos objetivos: a gestão do design busca reduzir tempo e custos com o objetivo de oferecer ao cliente preço mais competitivo e mais lançamentos, gerando mais lucro para a empresa. 0 design sustentável busca evitar desperdícios, consumir menos energia, utilizar menos matéria prima, reusar o que for possível, porém com o objetivo de fazer melhor uso dos recursos disponíveis, e como consequência, reduzir custos de produção e logística, principalmente. Apesar de oferecerem benefícios próximos, seus objetivos se distanciam nesse ponto, o que não impede de agir de forma complementar. Porém é importante que quando as ferramentas estiverem bem implementadas e consolidadas na realidade empresarial, haja diálogo entre a gestão do design estratégico, que lida com consumo, comportamentos e tendências, e o design sustentável agindo de forma radical, propondo rupturas sustentáveis nos alicerces da empresa, não mais agindo de modo incremental. Esse processo poderá unir os objetivos de ambas ferramentas bem alinhado a visão e missão defendida pela empresa. 


\section{CONCLUSÃO}

Gestão do Design e Design Sustentável têm sido utilizados como forma de agregar valor e diferenciação para a empresa, aumentando a probabilidade de êxito comercial/sustentável dos produtos. Porém é raro empresas que utilizem as duas ferramentas juntas, apesar de oferecerem vários benefícios parecidos ou complementares. São também similares em relação a visão sistêmica e pró atividade necessárias para serem realmente eficazes em seus objetivos.

A abertura do diálogo entre a gestão do design e o design sustentável representa um marco diferenciador na empresa e sua relação com o mercado e seus consumidores. Vai além de uma estratégia de ação empresarial, na medida em que traz intrinsecamente o potencial de se incorporar e se alinhar aos preceitos defendidos nos conceitos de visão e missão da empresa.

Um design bem gerido, com processos e propósitos claros, simplifica a implementação de design sustentável na empresa, ou seja, a gestão do design pode levar ao design sustentável, ainda que apresentem arestas. O cuidado que se deve tomar é de alinhar os objetivos de cada ferramenta à visão e missão da empresa, quando as primeiras estiverem bem consolidadas.

\section{REFERÊNCIAS}

BRASIL. Lei no 6.938, de 31 de agosto de 1981. Dispõe sobre a Política Nacional de Meio Ambiente, seus fins e mecanismos de formulação e aplicação, e dá outras providências. Disponível em: <http://www.planalto.gov.br/ccivil_03/leis/L6938.htm> . Acesso em: 12. jul. 2016.

CARNASCIALI, Rafael Matta. Gestão do Design: Contribuições da gestão da qualidade para a construção de parâmetros para avaliar o bom design. 2014. 165f. Dissertação (Mestrado) - Universidade Federal do Paraná, Curso de Pós-Graduação em Design.

CHAVES, L. I. (2009). Panorama do design para a sustentabilidade. Simpósio Paranaense de Design Sustentável, (pp. 69-75). Curitiba.

GUELERE FILHO, A. (2009). A inserção do design sustentável em um modelo de referência para a gestão do desenvolvimento de produtos. Simpósio Paranaense de Design Sustentável, (p. 17 a 24). Curitiba.

GUELERE FILHO, A., PIGOSSO, D. C., ROZENFELD, H., \& OMETTO, A. R. (2008). Ecodesign: Métodos e ferramentas. XXVIII Encontro Nacional de Engenharia de Produção. Rio de Janeiro.

KLONH, S. C. (2009). Design e o fim do ciclo de vida dos produtos. Simpósio Brasileiro de Design Sustentável. São Paulo.

LEE, Timothy Galpin J.; BELL, Whitttington Greg. Is your sustainability strategy sustainable? Creating a culture of sustainability. 2015. Corporate Governance, Vol. 15 Iss 1 pp. 1 - 17. Disponível na internet por http em: <http://www.emeraldinsight.com/doi/pdfplus/10.1108/CG-01-2013-0004>. Acesso em 19 jul. 2016 
MARTINS, R. F., \& MERINO, E. A. (2008). A Gestão do Design como Estratégia Organizacional. Londrina: EDUEL.

PETERSEN, Søren Ingomar; KIM, Jieun; MOZOTA, Brigitte Borja de. Managing Design driven innovation through the use of design scorecards. In: the value of design research, 11. 2015, Paris.

PLENTZ, Natália Debeluck; BERNARDES, Maurício Moreira e Silva. Proposição de um sistema de indicadores para avaliar a competitividade através de indicadores de gestão do design. Porto Alegre: Marcavisual, 2015. 77 p. Disponível em:

<http://www.ufrgs.br/icd/wpcontent/uploads/2015/01/Sistema-de-Indicadores-deInovação-Competitividade-e-Design-para-empresasdesenvolvedoras-deprodutos..pdf>. Acesso em: 19 jul. 2016. 